\title{
The Permeation and Practice of Aesthetic Education in College English Teaching
}

\author{
Wanli Zhang \\ Zaozhuang University, Shandong, China, 277300
}

Keywords: aesthetic education; College English; infiltration; practice

Abstract: Aesthetic education in College English teaching can stimulate students in learning English and help them establish correct values. The content of College English aesthetic education includes vocabulary aesthetic education, structural aesthetic education and phonetic aesthetic education. Therefore, teachers should carefully study college English curriculum standards and strengthen their professional competence in the implementation of American English teaching.

With the increasingly close international exchanges, under the situation of open development, the compatibility of international culture is stronger. English has become the universal language in the world. Excellent English level is an effective weapon to enhance the comprehensive strength of College students. English is not only a course for college students, but also a necessary skill for the survival and development of students in modern society. It is also a social development for students. Basic requirements. Therefore, College English teaching should strengthen studentship training, integrate aesthetic education into college English teaching, adjust and optimize teaching, and promote college English teaching and students' performance.

\section{The Function of Aesthetic Education in College English Teaching}

\subsection{Arouse Uninteresting in Learning English}

Interest is like a catalyst, which promotes people to actively explore new knowledge and develop new skills. The infiltration of aesthetic education into English teaching can combine the characteristics of aesthetic education such as image, emotion and pleasure with the boring and profound teaching knowledge, and establish self-fulfilment efficiency. Let the students soar in the beauty of English and the pleasure of communication, enjoy the beauty while improving the appreciation of the beauty of English.

Aesthetic education teaching actively explores teaching methods, attaches importance to visual images and sounds to assist English learning, and creates real English dimension space and language situation, so that students can easily enter the best state of association, cognition and behavior psychologically. Develop the course of English film appreciation, through introducing the background of the film story, explaining key words and sentence patterns, appreciating classical lines, and evaluating the theme of the film, to deepen misunderstanding of British and American culture, stimulate students' learning motivation, and cultivate student aesthetic ability and 
humanistic accomplishment.

\subsection{Establishing Correct Values}

College English requires students to use English thinking on the basis of mastering English language proficiently to recognize the customs, ethics and humanistic characteristics of western-speaking countries, improve their own ethical literacy and aesthetic ability, become an ambassador of cross-cultural communication, establish correct values, and have a strong sense of social responsibility. The new curriculum reform concept puts forward higher requirements for improving humanistic quality. Aesthetic education has strong humanistic color and positive and correct aesthetic concept, which can guide students to pursue the integrity of spiritual value while mastering English knowledge, establish correct outlook on life and values, and thus shape sound personality quality.

\section{Contents of Aesthetic Education Teaching in College English}

Ian Guangzhou, a linguist, believes that any language is an art in itself and contains certain aesthetic features. The integration of professional teaching concepts in College English teaching at different levels provides an opportunity for English aesthetic education. Therefore, no matter which level of classes, they should integrate aesthetic concepts as much as possible. When compiling and researching English teaching plans, English aesthetic education materials should be carefully constructed. Vocabulary, idioms, rhetoric, prosody and metrics should be permeated into the guidance of English aesthetic education. In order to broaden the aesthetic horizon of College English teaching, we boldly quote the hot topics of economy, politics and society as teaching materials, which are embodied in three aspects: vocabulary aesthetic education, structural aesthetic education and phonetic aesthetic education.

\subsection{Vocabulary Aesthetic Education Teaching}

In order to permeate the beauty of English vocabulary in teaching, we should extend the aesthetic education meaning (deep information) and aesthetic color (outer information) of vocabulary while teaching the basic vocabulary of vocabulary. We should grasp the amount of information besides aesthetic education according to the acceptance ability of classmates. For example, the word Narcissus means Narcissus. Anarchistic is the adjective of self-intoxication and narcissism, the gap between the two A lot. How to imagine synaesthesia? The story of Echo and Narcissus in ancient Greek mythology can be briefly narrated: Echo falls in love with Narcissus, but Narcissus can not extricate itself from narcissism all day long, and finally languishes and dies into Narcissus, so Car-c is the name of Narcissus. When is sus is named, its adjective transformation becomes the meaning of narcissism and self-intoxication. There is a strong contrast between the aesthetic thinking of English vocabulary and that of Chinese people. We should infiltrate this idea in continuous feedback teaching. For example, Castle has a vague meaning while Shepherd has a kind meaning.

\subsection{Teaching of Structural Aesthetic Education}

In order to penetrate the beauty of English sentence structure in teaching, under certain circumstances, sentences, paragraphs and texts can deepen the theme according to the principle of formal aesthetics, and achieve perfect artistic conception by means of structural aesthetic forms such as parallelism, repetition, inversion and contrast. For example, in his inaugural speech, 
Kennedy said: As knot what you can count on can do for you. Ask what you can do for your country. (Ask not what your country can do for you, but what you can do for your country.) Compared with the public war, Kennedy's self-confidence and decisiveness are revealed. Another example is the advertisement for Rolex watches:Unlike me, my Rolex never needs rest. The personification shows that Rolex watches are dynamic, accurate and can provide 24-hour eternal service. Simple and powerful sentence patterns are a major feature of Chinese language. English also has four-character structure, which is vivid and expressive, as shown in figure 1:

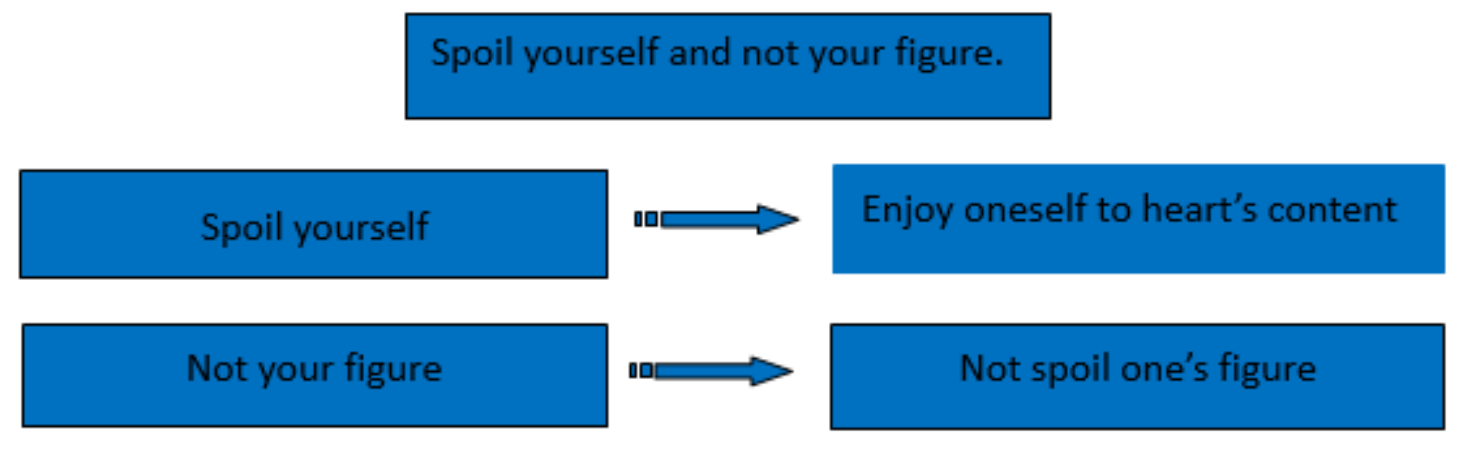

Figure 1.Teaching of Structural Aesthetic Education

\subsection{Phonetic Aesthetic Education Teaching}

The beauty of English intonation should be permeated into teaching. The importance, ups and downs, rhythm and rhythm of spoken English are also the infection and Enlightenment of beauty. The vivid aesthetic feeling can stimulate college studentship understanding and feeling of English beauty, and stimulate their strong thirst for knowledge and aesthetic experience of English. For English teachers, clear blasting tone, euphemistic fluctuating intonation and rhyme can take the lead in capturing studentships, making English classroom artistic appeal, and achieving the effect of "emotional and overflowing words".

Firstly, phonetic symbols are the basis of English pronunciation. The basic English education level is uneven. When enjoying good English education at the University stage, we can avoid non-standard phonetic symbols and properly popularize phonetic knowledge. Secondly, we should accurately divide the pause of sentences, and remember that the information unit should regulate the reading of sentences, such as: If the university is not in a steady state, then it is changing and such change is described by psychologists. There should be a pause where the double vertical lines appear in the sentence, so that a certain sense of rhythm can be formed. Thirdly, we should use the foot length to highlight the change of rhythm and the sense of rhythm, such as an advertisement on American flights. Typical setbacks, short and powerful, add a little sense of humor.

\section{Teaching Suggestions for Effective Implementation of Aesthetic Education}

Aesthetic education teaching mode does not have obvious teaching characteristics and teaching behavior, but through little changes, infiltration at all times, strengthen unaesthetic education awareness, unconsciously, improve English performance. At the same time, with the development of aesthetic education in College English teaching, English interpersonal charm, working level and professional accomplishment are constantly improving and perfecting. In the teaching work, beauty is found, applied and displayed, so as to promote the sustainable development of College English teaching. As shown in Table 1: 
Table 1.Teaching situation

\begin{tabular}{|c|c|}
\hline Teaching situation & SD \\
\hline Vocabulary Aesthetic Education Teaching & 2.3426 \\
\hline Teaching of Structural Aesthetic Education & 3.0127 \\
\hline Phonetic Aesthetic Education Teaching & 2.7831 \\
\hline
\end{tabular}

\subsection{Careful Study of College English Curriculum Standards}

College English curriculum standard is the basis of curriculum compilation and research and teaching curriculum arrangement. Only when teachers carefully study the new curriculum standards and thoroughly understand the textbooks can they integrate aesthetic education into teaching. After guiding students to explore, students can appreciate the aesthetic sense of vocabulary and the use of contradictory rhetoric, and explore the interest of English classroom.

Excellent standard spoken English expression can directly affect studentship pronunciation. Teachers should pay attention to the strength of the phonetic symbols of words, the rise and fall of intonation, the setbacks of sentences and the coherence of language. Teachers can demonstrate the correct pronunciation for students, read short film articles aloud, through teachers' setbacks, priorities of pronunciation, and draw colorful, vivid images, clear and fluent reading aloud. Let students feel the beauty of the language, so as to standardize oral pronunciation. Teachers should also try their best to adopt full English teaching in teaching, create a strong environment for oral English communication, and encourage students to try, speak boldly and speak actively.

\subsection{Strengthen one's Own Professional Ability and Enrich Knowledge Reserve}

Integrating aesthetic education into English teaching not only requires teachers to be familiar with college English teaching standards and objectives, to understand the beauty of English textbooks, but also to constantly strengthen their professional competence. Articles in College English textbooks involve politics, economy, history, culture, science and technology. If teachers do not have sufficient knowledge reserve, aesthetic education teaching will become a nonsense. Therefore, if we want to carry out aesthetic education flexibly, we should reserve abundant professional knowledge, broaden our knowledge, improve our English appreciation level, and make effective use of aesthetic education content to revitalize the classroom vitality.

\section{Conclusion}

To sum up, English is a comprehensive subject. It is not only professional, but also artistic. College English teaching should attach importance to instrumentality education and actively apply aesthetic education teaching mode to English teaching. Through aesthetic education teaching mode, teachers' teaching method and reteaching language beauty, it fully reflects the artistic beauty of English curriculum and fully displays it. Effective teaching of English aesthetic education can effectively improve uninteresting in learning, stimulate their active learning, expand their knowledge of English, and improve their oral English expression ability, so that students can effectively apply the knowledge to real life, embody their own cultural literacy and artistic aesthetic ability, and lay a solid foundation for the sustainable development of students and schools.

\section{References}

[1] Chen Xiaoping. Reflections on Aesthetic Education in College English Teaching [J].Off-campus Education, 2011, 
(20): 23-24.

[2] Chaos Na. Exploration of Aesthetic Education in College English Teaching [J]. Private Science and Technology, 2011, (11): 33-34.

[3] Chaos Dangling. Aesthetic Education Infiltration in College English Teaching [J]. Journal of Beijing University of Aeronautics and Astronautics (Beijing University of Aeronautics and Astronautics)Social Sciences Edition, 2008 (6).

[4] Li Lei. Research on Aesthetic Education Contents and Teaching Status in Reading Materials of English Textbooks for Senior High Schools [D]. Shanghai Normal University, 2011._4

[5] Ni Lanzhou. An Analysis of Aesthetic Education Infiltration in College English Teaching [J]. Journal of Amusing College of Education, 2014 (3). 